\title{
Promoting Cooperation and Collaboration in a Web-based Learning Environment
}

\author{
Fay Sudweeks \\ Murdoch University, Perth, Australia \\ sudweeks@murdoch.edu.au
}

\begin{abstract}
Web-based learning environments provide an attractive method for information dissemination, but in many instances they can be just electronic equivalents of printed course materials. Appropriate learning objectives and pedgagogical strategies are minimal or non-existent. Too often web-based learning environments lack cooperative and collaborative activities with the unintended consequence of feelings of social isolation. This paper describes a case study in which critical elements of online learning settings (Oliver, 2001) were implemented along with essential attributes for effective teamwork. Analyses of student que stionnaires indicate that students gained significant benefits from the instructional design of both the learning environment and the collaborative activity - without meeting face-to-face.
\end{abstract}

Keywords : Flexible learning, teamwork, groupwork, web-based learning environments, social interaction, collaboration, cooperative learning

\section{Introduction}

E-learning has been touted as the panacea to many problems associated with higher education, such as escalating education costs, reduced funding, and the pressure for lecturers to produce web-based material for both on-campus and off-campus students. Among the perceived benefits of e-learning are the possibilities of attracting new markets and new students, creating level pla ying fields in terms of equity and access, and reducing program delivery costs (Oliver, 2001).

Too often web-based learning environments are simply an electronic version of existing teaching material. These environments are adopted because of their technical innovativeness with little thought given to integrating the medium with learning objectives and pedagogical strategies (Coppola, Hiltz and Rotter, 2001). Creating web pages for a course does provide the glue that binds previously separate elements. However, creating a learning community with technologies involves more than a few links on the web, it involves supporting students in their efforts to share common tasks and build interdependent relationships (Palloff and Pratt, 1999)

To stimulate the creation of effective e-learning environments, Oliver (2001) has developed a framework of three interconnecting elements as critical components. The three critical elements are learning tasks, learning resources and learning supports (Table 1).

The most significant deficit of many web-based learning environments, however, are appropriate social

Material published as part of these proceedings, either on-line or in print, is copyrighted by Informing Science. Permission to make digital or paper copy of part or all of these works for personal or classroom use is granted without fee provided that the copies are not made or distributed for profit or commercial advantage AND that copies 1) bear this notice in full and 2) give the full citation on the first page. It is permissible to abstract these works so long as credit is given. To copy in all other cases or to republish or to post on a server or to redistribute to lists requires specific permission from the publisher at Publisher@InformingScience.org and collaborative activities resulting in unintended consequences of feelings of social isolation among the student population. In other words, information and communication technologies can separate rather than connect students. 


\begin{tabular}{|l|l|}
\hline Learning design elements & Description \\
\hline Learning tasks & $\begin{array}{l}\text { The activities, problems, interactions used to engage the learners } \\
\text { and on which learning is based. }\end{array}$ \\
\hline Learning resources & $\begin{array}{l}\text { The content, information and resources with which the learners } \\
\text { interact and upon which learning is based. }\end{array}$ \\
\hline Learning supports & $\begin{array}{l}\text { The scaffolds, structures, encouragements, motivations, } \\
\text { assistances and connections used to support learning. }\end{array}$ \\
\hline
\end{tabular}

Table 1: Framework describing critical elements of online learning settings (from Oliver, 2001, p.407).

More than any other teaching medium, however, web-based learning environments have the potential to fully exploit theories of social and active learning through cooperative and collaborative activities (Vygotsky, 1978; Sudweeks and Simoff, 2000; Tiffin and Rajasingham, 1995). Dillenbourg and Schne ider (1995) distinguish between cooperative and collaborative learning. Cooperative learning is "... a protocol in which the task is in advance split into subtasks that the partners solve independently". Collaborative learning is where "... two or more subjects build synchronously and interactively a joint solution to some problem". There is considerable evidence that cooperative learning enhances academic learning (Johnson, Johnson and Stanne, 2000; Tang, 1993). Teams and teamwork can not only facilitate cooperation and collaboration among students, but also promote deep learning through interaction, problem solving and dialogue (Johnson and Johnson, 1999).

As any educator who uses team work as a form of assessment is aware, successful team work does not just happen. Effective team work requires a number of attributes. Researchers have identified a number of attributes necessary for effective team work including communication (Harris and Harris, 1996), interdependence (Johnson and Johnson, 1999), leadership (Bradley and Frederic, 1997), and accountability (Smith, 1996).

This paper presents an explorative case study in which the elements of Oliver's (2001) framework of effective online learning settings were implemented into the web-based learning environment. To encourage more social cooperative learning, a team project was introduced as a component of the unit's assessment incorporating the attributes of team work into the project design. The development of the team project was a process of planning and evaluation of cooperative learning, designed to connect multimodel and geographically disparate undergraduate students at Murdoch University in Australia.

\section{Case Study}

The case study is an undergraduate course in Organisational Informatics at Murdoch University. In 2002, the course had an enrolment of 156 students. The course design has key components of weekly online tutorials in a chat room and an online team project. Each tutorial is devoted to a particular topic that is complementary to lectures and course materials. The tutorials are intended to facilitate students' construction of knowledge through participation and reflection (Sudweeks and Simoff, 2000). There are six areas of assessment: (i) moderation of one online tutorial session; (ii) participation in the tutorials; (iii) weekly reflective journals which included a critique of at least one required reading on the weekly topic and a reflection on the online tutorial discussions; (iv) team project; (v) research essay; and (vi) end-of-semester examination. 


\section{Web-Based Learning Environment}

The web-based learning environment is WebCT, which is platform independent and is accessed using a web browser. The environment has been customised specifically for the Organisational Informatics unit of study. The course home page was designed to simplify access and navigation as well as to conform with Oliver's (2001) framework. It features three types of material: (i) learning tasks; (ii) learning resources; and (iii) learning support. Learning tasks include tools for interactions to engage the learners, i.e. forums (public and private), chat rooms, and a shared whiteboard, and guidelines for activities and problems, i.e. descriptive requirements for reflective journals, team project and research essay. Learning resources include content and information upon which learning is based, i.e. lecture notes, a collection of downloadable readings used for discussion topics for the weekly tutorials, transcripts of synchronous online tutorials, and a web portal (links to relevant websites). Learner supports include scaffolds and structures to support learning, i.e. calendar, guidelines for team work and for tutorial presenters, course outline, and tutors' photos and contact information (Table 2).

\begin{tabular}{|l|l|}
\hline Learning design elements & Artifacts \\
\hline Learning tasks & $\begin{array}{l}\text { Public bulletin board; private forums; whiteboard; requirements } \\
\text { for reflective journals; team project and research essay. }\end{array}$ \\
\hline Learning resources & $\begin{array}{l}\text { Lecture notes; readings; transcripts of online tutorials; web } \\
\text { portal. }\end{array}$ \\
\hline Learning supports & $\begin{array}{l}\text { Course outline; calendar; guidelines for team work and tutorial } \\
\text { presentations; tutors' photo, email and contact information. }\end{array}$ \\
\hline
\end{tabular}

Table 2. Web-based Learning Environment

\section{Team Project}

"Lurking" is a feature of discussion groups where some subscribers passively read posts but fail to contribute to the discussions. In the virtual tutorial, it is all too easy to log on and create a presence but take no part in the tutorial. Similarly, "hitchhiking" is a common feature of team projects, where some team members do not fulfill their responsibilities yet are awarded the same grade as their more responsible counterparts (Kaufman, Felder and Fuller, 1999). The team project, therefore, needed to be designed in a way that would minimise hitchhiking while facilitating and motivating cooperative learning.

The team project involved the development of a proposal for a major event. Events chosen included weddings, funerals, safaris, conferences, product launches, $21^{\text {st }}$ birthday parties, concerts, movie premiers and a store opening. The project was intended to satisfy the requirements for effective team work as described above - that is, communication, interdependence, leadership and accountability.

\section{Communication}

The uniqueness of the project was in the restriction of communication among team me mbers to textbased mediated communication only. The communication tools available were private email, WebCT mail, bulletin board, private forums, WebCT chat rooms, IRC, ICQ, instant me ssaging and SMS.

The restriction of not being able to meet face-to-face had two distinct advantages:

1. providing a level playing field for students studying in different modes (part-time, full-time, externally) and in different locations (two campuses in Perth, national students located in other areas of the state and country, international students located in Italy, Singapore and Netherlands), and 
2. providing a practical application of theoretical issues covered in the unit, such as computermediated communication, computer-supported collaborative work, and virtual organisations.

In the first week of the semester, tutors randomly assigned students in their tutorial groups to project teams of 4 students each. The 156 students enrolled in the unit were thus assigned to one of 39 project teams. However, simply assigning students to teams to work on a collaborative project does not necessarily mean that the activity will be cooperative. In order for cooperative learning to occur, a collaborative project must be "structured to create positive interdependence as well as individual accountability" (McGookin, 2002).

Each team was required to submit two files on a disk: (i) a PowerPoint file of the proposed event including alternative plans, rationale for accepting one plan, budget and summary of communication; and (ii) an Excel file of a communication diary with worksheets for each communication type, documenting frequency, length, topic and reflection of each communication event (see Figure 1 for an example of a communication diary).

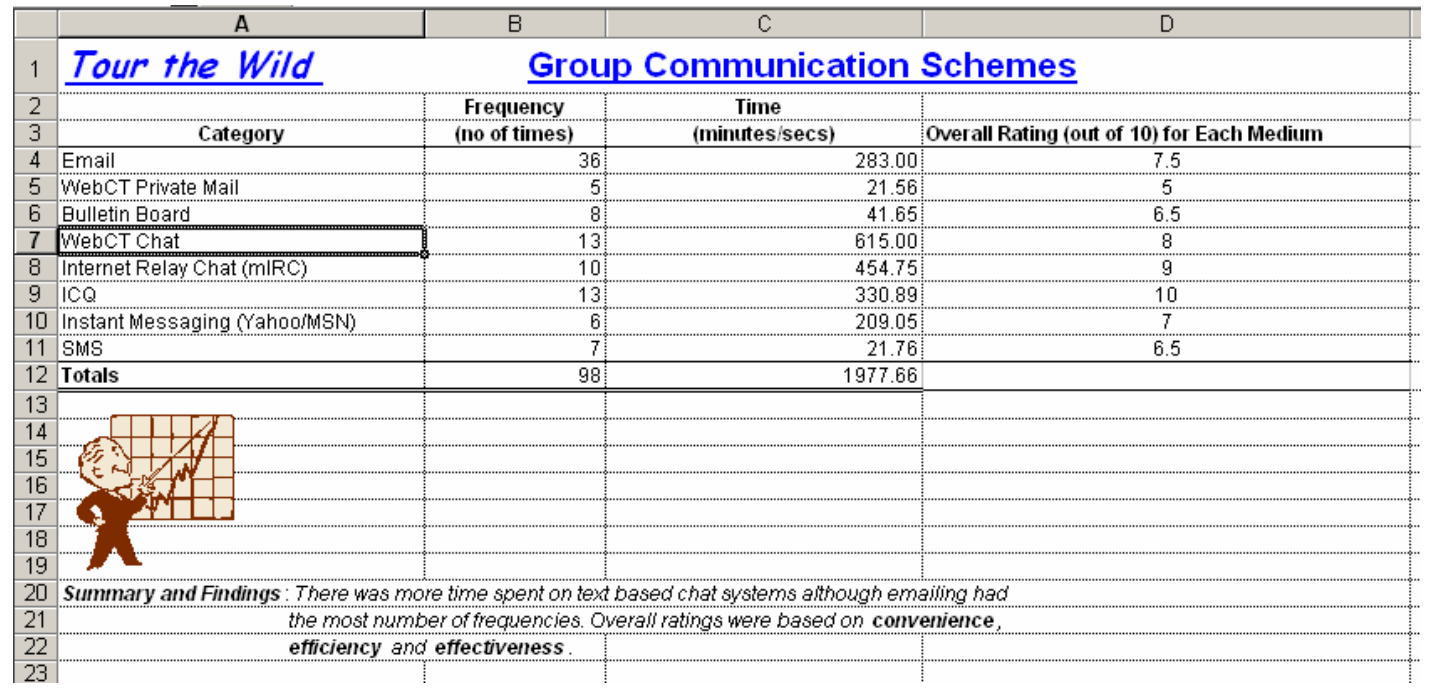

Figure 1. Example of Communication Diary

\section{Interdependence}

To facilitate cooperative learning, each team member had a choice of four "roles" in the team project client, consultant, researcher or presenter. The client was responsible for providing a budget and detailed requirements for the event. The consultant prepared plans, detailed costings and implementation steps. The researcher kept a diary of the time, frequency, topic and reflection of each communication channel. The presenter organised the information and prepared a PowerPoint file for an online presentation to their tutorial group in the final week of semester. The defined roles gave a clear structure and division of tasks within the team, while still retaining interdependency.

\section{Leadership}

As it was necessary for the researcher to be aware of all communication (and, ideally, present), the researcher role was also the leadership role and was therefore responsible for keeping the project moving forward.

\section{Accountability}

The course coordinator and a tutor were assigned to each private forum. Chat room discussions were logged, archived, and made available for the team participating in the discussions. The open communi- 
cation had the dual effect of providing scaffolding and accountability. If any dispute occurred about work participation, transcripts of meetings and communication could be consulted.

Accountability was also achieved by using a self-assessment strategy within the teams. A project was marked as a team effort and the default was that each member of the team receive the team mark. However, the team could request that marks be distributed according to participation, which could be an unequal distribution.

\section{Results}

\section{Communication}

The use of communication tools varied considerably across all teams (Figure 2). On average, asynchronous media were used the most frequently, with email the most popular (41\%), followed by the private forums set up on WebCT specifically for the team projects (20\%). However, other media were used extensively by a small number of teams. For example, although instant messaging represented only an average of 5\% of communication across all teams, one team used it almost exclusively (476 times or $95.2 \%$ of its communication). Similarly, although SMS represented only an average of 5\% of communication across all teams, one team used it 85 times (63.9\% of its communication).

There was also considerable variation in the duration of communication across teams (Figure 3). Although the average time spent in communicating across all media was 460 minutes, one team spent only 41 minutes while another team spent 1978 minutes. On average, teams spent the most time on email and WebCT chat but, again, there were outliers. For example, instant me ssaging accounted for only $4 \%-$ or 1194 minutes - of the average duration of communication. Almost half of this time (596 minutes) was used by just one team.

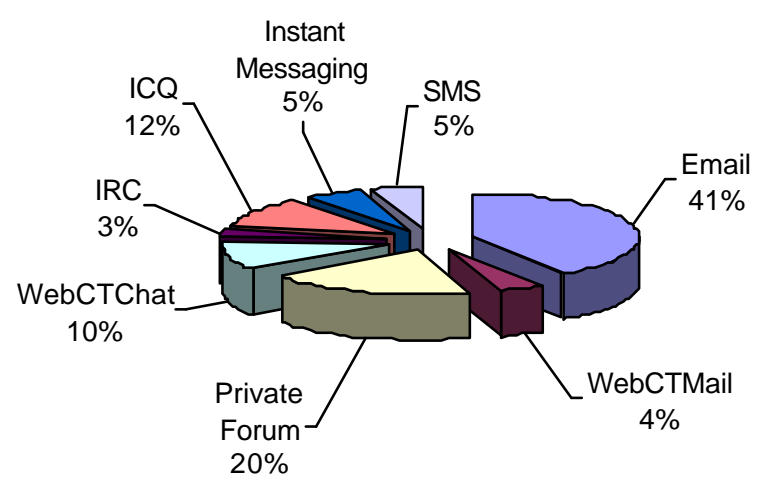

Figure 2. Frequency of communication media across teams

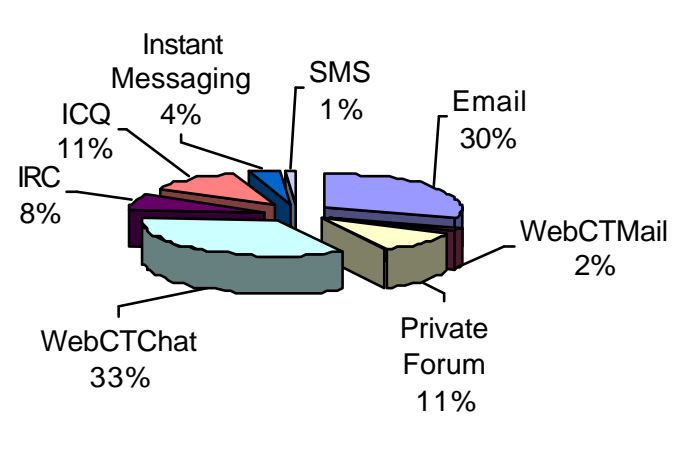

Figure 3. Duration of communication media across teams

\section{Survey}

In the final week of semester, the students were surveyed about different facets of their (i) team communication, (ii) team dynamics, (iii) perceptions of the team project, (iv) perceptions of e-learning generally, and (v) comments. There were 49 respondents to the survey, of whom $53 \%$ were male and $47 \%$ were female. 


\section{Team communication}

The first five questions of the survey were concerned with team communication. Almost half (49\%) of the respondents reported a very high interaction with their team but almost as many (40.8\%) found it difficult to get in touch with team members.

When asked to specifically compare their discussions in an online team with a face-to-face team approximately one quarter of the respondents (26.5\%) felt more comfortable. Despite reporting feelings of discomfort in discussions, $38.8 \%$ are more likely to share their opinions and $46.9 \%$ are more likely to learn more about other students' opinions.

\section{Team dynamics}

The second set of five questions were concerned with team dynamics. In more than half of the teams (55.1\%) there was one person who took on the responsibility of keeping the team's activities on track.

The majority of teams were congenial with a high level of agreement among members. More than half the teams found it easy to reach consensus $(57.2 \%)$, enjoyed working together $(61.2 \%)$ and expressed interesting in meeting face-to-face $(59.2 \%)$.

The student population at Murdoch University is culturally diverse and the teams represent this campuswide diversity. The countries of origin reported by team members include Brunei, England, Indonesia, Ireland, Hong Kong, Malaysia, Pakistan, Poland, Singapore, South Korea, Sweden and Yugoslavia. Almost half of the students $(47 \%)$ reported that they appreciated the learning experience of working in culturally diverse teams.

\section{The project}

The third set of five questions were concerned with the project itself. It is clear that sufficient information was given in the project guidelines as three-quarters $(75.6 \%)$ of the students reported they understood what they were expected to do and only a small percentage (10.5\%) found the project difficult.

More than two-thirds of students $(69.4 \%)$ reported a sense of autonomy in being able to work independently on their own tasks.

Although more than a third of the students (38.8\%) were in teams in which all participants did not work equally well, almost two-thirds (61.2\%) found the team project a positive experience.

\section{E-Learning}

The fourth set of five questions were concerned with e-learning. Overall, working in a web-based learning environment proved to facilitate learning. Approximately three-quarters of the students reported an effective learning experience $(77.5 \%)$, a greater understanding of working in a virtual team $(79.6 \%)$, and being responsible for their own learning $(73.5 \%)$. More than a third of the students $(40.8 \%)$ also found the project a practical application of the theoretical aspects of the unit.

More than half of the students $(51 \%)$ did not mind having tutor and coordinator access to team discussions. It is not clear, though, whether this was perceived as an advantage or just a benign form of monitoring.

\section{Comments}

Most of the comments were positive, e.g.

"I think that the on-line group is a great idea for university courses. Why: It's so easy to see who is at meetings, record minutes, have tasks pinpointed. You have time to think before answering via email and the ability to get good written feedback. Maybe I was lucky in that the team I was part of were excellent. So far it has been one of the best group experiences." 
“... no fights only good discussions, everyone has done their bit excellent, it has been a pleasure to work in this group."

However, the experiences of a few teams were not as positive, e.g.

"Communication was difficult because not all group members could access all channels."

"One of the team members was a bit difficult to get in touch with - took several days before he answered email and he did not show up in the chat room."

\section{Conclusions}

This case study described a team project incorporating key attributes of effective team work - communication, interdependence, leadership and accountability - in a web-based learning environment providing learning tasks, learning resources and learning supports.

Working with students drawn from a wide spectrum in terms of location, access to campus facilities and cultural backgrounds is difficult. Engaging this diverse group of students in social interaction to facilitate learning through cooperation and collaboration is enormously difficult. The online team project is one way of addressing the needs of this diverse population.

Of the 39 teams, 7 teams requested variation in grading: 2 requested one member of their team receive a grade less; 2 requested one member receive a pass grade of 50\%; 3 requested one member receive $0 \%$.

Overall, though, student self-reports indicated a very high level of satisfaction with the team process, and this is supported by the quality of the work produced - more than two thirds $(69 \%)$ of the teams attained a higher grade, i.e. $70 \%$ or more.

The results indicate that to create a learning community and effective online learning, key attributes should be carefully integrated into any team activities. The design of the e-learning environment should incorporate appropriate tasks, resources and supports. Further research is needed to test these frameworks more rigorously. It is intended to incorporate the team project into the course again and to compare the results of different cohort of students with the results of this study.

\section{Acknowledgements}

Thanks to Sean Grosse, Simone Heaperman, John Krummel, Jozef Loermans, Simeon Simoff (University of Technology, Sydney), Nathan Vivian and Ray Webster (Edith Cowan University) for suggestions in the development of the team project.

\section{References}

Bradley, J. H. \& Frederic, J. H. (1997). The effect of personality type on team performance, Journal of Management Development, 16(5), 337-353.

Coppola, N., Hiltz, S. R. \& Rotter, N. (2001) Becoming a virtual professor: Pedagogical roles and ALN, 34th Annual Hawaii International Conference on System Sciences, Maui, Hawaii, IEEE Computer Society, pp. 1003.

Dillenbourg, P. \& Schneider, D. (1995). Collaborative learning and the Internet. Accessed 18 August 1998, http://tecfa.unige.ch/tecfa/research/CMC/colla/iccai95 1.html.

Harris, P. R. \& Harris, K. G. (1996). Managing effectively through teams. Team Performance Management: An International Journal, 2(3), 23-36.

Johnson, D. W., Johnson, R. \& Stanne, M. B. (2000). Cooperative learning methods: A meta-analysis. Cooperative Learning Center at the University of Minnesota. Accessed 29 October 2002, http://www.clcrc.com/pages/cl-methods.html.

Johnson, D. W. \& Johnson, R. T. (1999). Learning together and alone: Cooperative, competitive, and individualistic leaming, 5th ed. Allyn and Bacon, Needham Heights, Mass achusetts.

Kaufman, D. B., Felder, R. M. \& Fuller, H. (1999). Peer ratings in cooperative learning teams. Proceedings of the 1999 Annual ASEE Meeting, ASEE. 
McGookin, M. (2002). I can't let them down! Affiliative motivation and co-operative learning in higher education. In A. Goody, J. Herrington and M. Northcote (ed.), Proceedings of the 2002 Annual International Conference of the Higher Education Research and Development Society of Australia, HERDSA, Perth, WA, pp. 417-425.

Oliver, R. (2001). Developing e-learning environments that support knowledge construction in higher education. In S. Stoney and J. Burn (ed.), Working for Excellence in the E-conomy, We-B Centre, Churchlands, Australia, pp. 407-416.

Palloff, R. M. and Pratt, K. (1999). Building learning communities in cyberspace: Effective strategies for the online classroom, Jossey-Bass, San Francisco.

Smith, K. (1996). Cooperative learning: Make groupwork work. New Directions for Teaching and Learning, 67(Fall), 71-82.

Sudweeks, F. \& Simoff, S. (2000). Participation and reflection in virtual workshops. Proceedings Western Australian Workshop on Information Systems Research, Edith Cown Un iversity.

Tang, K. C. C. (1993). Spontaneous collaborative learning: A new dimension in student learning experience? Higher Education Research and Development, 12(2), 115-130.

Tiffin, J. \& Rajasingham, L. (1995). In search of the virtual class: Education in an information society. Routledge, London.

Vygotsky, L. S. (1978). Mind in society: The development of the higher psychological processes. Harvard University Press, Cambridge, MA.

\section{Biography}

Fay Sudweeks is a Senior Lecturer in Information Systems at Murdoch University. She has Bachelor (Psychology and Sociology) and Master (Cognitive Science) degrees from the Unive rsity of New South Wales and is a PhD candidate in Information Systems. Her current research interests are social, cultural and economic aspects of computer-mediated communication and CSCW, group dynamics, e-commerce and e-learning. She has published 6 edited books, 8 edited proceedings, and more than 50 papers in journals, books and conference proceedings. She is on the editorial review board of the International Journal of e-Learning, Journal of Computer-Mediated Communication, Journal of Electronic Commerce in Organizations, and Journal of Electronic Commerce Research. She has co-chaired three international and interdisciplinary conferences on Cultural Attitudes towards Technology and Communication (CATaC). Fay has given invited talks in numerous countries including the USA, South Africa, Russia, Germany, Israel, and Sweden. 